\title{
A REVOLUÇÃO RUSSA EM PERSPECTIVA HISTÓRICA E COMPARADA
}

Modesto Florenzano

Nesta exposição procurarei, com o olhar e a perspectiva do historiador de história moderna, que é a minha, comparar a Revolução Russa com a Revolução Francesa de 1789 e a Revolução Inglesa de 1640. Não há necessidade de lembrar aqui que a Revolução Russa já foi, e continua sendo, comparada a outras Revoluções, quer a ela anteriores no tempo, como, por exemplo, a norte-americana de 1776, quer a ela posteriores, como a chinesa de $1949^{1}$. De minha parte, entre as muitas razões que poderia oferecer aqui para justificar o porquê de comparar a Revolução Russa com as Revoluções Francesa e Inglesa, e apenas com elas, mencionarei duas: uma razão de ordem histórica, e outra, historiográfica.

Em termos de história, é impossível compreender bem, ou a fundo, a Revolução Russa, fazendo-se abstração da Revolução Francesa de 1789, bem como compreender esta última, fazendo-se abstração da Revolução Inglesa de 1640. A presença da Revolução Francesa e de seus desdobramen-

\footnotetext{
${ }^{1}$ Ver, entre outros, os livros de Crane Brinton (1958) um dos primeiros estudos comparativo das Revoluções Inglesa, Francesa, Norte-Americana e Russa, e de Theda Skocpol (1985).
} 
tos nas mentes dos revolucionários russos é um fato bastante conhecido para ser enfatizado aqui. Basta observar que, no caso dos dois maiores protagonistas de Outubro de 1917, Lenin e Trotsky, foi o profundo conhecimento que tiveram da Revolução Francesa que permitiu a ambos elaborar suas respectivas teorias revolucionárias.

Marc Ferro, historiador francês da Revolução Russa, observa que, na França, nos primeiros anos que se seguem à Revolução de 1917:

"Lenin era assimilado a Robespierre, e, com base nesse terreno conhecido, podiam-se opor partidários da 'indulgência' a partidários da 'intransigência'. Lenin eliminava os partidos, tal como Robespierre eliminara os girondinos, os indulgentes. Ora, os revolucionários russos analisavam os eventos um pouco do mesmo modo. Em alguns casos, Fevereiro de 1917 era comparado a 1789, e 42 Outubro, à ditadura jacobina; em outros, 1905, a 1917, Fevereiro de 1917, a 10 de agosto de 1792 (queda do rei) e Outubro ao Terror; logo após, passou-se a identificar a NEP com o Termidor. Com boa lógica, Bertrand Russel - em Prática e teoria do bolchevismo (1921) - esperava o advento de um Bonaparte" (Ferro, 1984, p. 56).

Por sua vez, o historiador Eric Hobsbawm, em livro que trata da historiografia da Revolução Francesa, assinala que "a luta da década de 1920 na União Soviética foi conduzida com acusações mútuas tiradas da Revolução Francesa”, e cita a frase de um comunista francês que, tendo convivido em Moscou com revolucionários russos, ao voltar para a França, em 1920, declarou maravilhado: "Eles conhecem a Revolução Francesa melhor do que nós!” (Hobsbawm, 1996, pp. 73 e 62).

Embora, sem dúvida, a presença da Revolução Inglesa nas mentes dos revolucionários franceses de 1789 não tenha sido tão generalizada e forte quanto a que acabamos de 
examinar, também não foi de pouca importância para não merecer ser lembrada aqui. Vejamos três exemplos: Mirabeau, que participara da tradução para o francês de uma história da Inglaterra, publicada em 1791 (e intitulada Histoire d'Angleterre depuis l'avènement de Jacques I jusqu'à la Révolution... et enrichie de notes. Par Mirabeau), exprimiu, segundo um testemunho, sua "vontade de instruir e influenciar a revolução que se abria pela narrativa da precedente"; nas memórias que Brissot, um dos líderes girondinos, escreveu antes de ir para a guilhotina em 1793, lê-se: "Esta idéia de revolução [...] passava com freqüência pela minha cabeça [...] A história de Carlos I e de Cromwell havia-me particularmente impressionado [...] Não me parecia impossível renovar esta revolução"; Napoleão, por sua vez, teria segredado a um intimo em 1797: "Não quero desempenhar o papel do general Monck" (Lutaud, 1990).

Ainda sobre a presença da Revolução Inglesa na Revolução Francesa, e permanecendo simultaneamente nestes dois planos, o da história e o da historiografia, considere-se a figura do historiador e político francês, François Guizot (1787-1874). Durante a Restauração na França, mais precisamente na década de 1820, Guizot, ao mesmo tempo em que proferia aulas no Collège de France, às quais muitos ouvintes assistiam, como o então jovem Aléxis de Tocqueville, não se descuidava de preparar e apressar o fim da Restauração, tão grande era a sua convicção de que isto estava, inevitavelmente, para acontecer. Não foi, portanto, um mero acaso o fato de ter sido ele, Guizot, o primeiro a interpretar os acontecimentos políticos ocorridos na Inglaterra em meados do século XVII como uma Revolução, numa publicação de 1826, precisamente intitulada História da Revolução Inglesa de $1640^{2}$.

\footnotetext{
${ }^{2}$ Sobre o lugar ocupado por este escrito de Guizot na historiografia da Revolução inglesa do século XVII, ver R.C. Richardson (1991).
} 
Guizot estava absolutamente convencido de que, assim como a Revolução Inglesa chegara ao fim com a Revolução Gloriosa de 1688-1689 o mesmo iria, mais cedo ou mais tarde, acontecer com a França. Pois não tinham as duas Revoluções, a Inglesa de 1640 e a Francesa de 1789, guardadas as devidas diferenças, passado pelas mesmas seqüências e fases? Com efeito, em ambas, uma vez derrubado o absolutismo (precipitado por um colapso financeiro dos respectivos Estados), abrira-se um período instável de monarquia constitucional, no qual a iniciativa do poder passara ao Parlamento, mas por causa da irredutibilidade do conflito entre a Corte e o Parlamento, e suas respectivas forças sociais e político-militares de sustentação, o conflito desaguara em guerra civil e civil-internacional, com o que se chegara à instalação de um regime revolucionário e republicano, a uma luta de vida e morte entre revolucionários moderados e radicais, seguindo-se a esta luta uma ditadura 44 pessoal e uma reação no interior da revolução vitoriosa; reação que, na França, conhecida como Termidor, aconteceu antes (em 1794) e não simultaneamente com a ditadura pessoal de Napoleão (a partir de 1799), como foi o caso com Cromwell na Inglaterra, o qual, ao tomar o poder, em 1647-1649, implementa a reação à Revolução (depois de a ter radicalizado) e a ditadura.

Tendo em mente as trajetórias, ou parábolas, percorridas pelas Revoluções Inglesa e Francesa - derrubada do absolutismo, monarquia parlamentar, guerra civil, república, reação termidoriana, ditadura pessoal, restauração, superação da restauração e encerramento da Revolução -, não deixa de ser impressionante constatar que, também na Revolução Russa, observam-se, mutatis mutandis, uma dinâmica e uma seqüência revolucionárias bastante semelhantes àquelas duas Revoluções. Com efeito, não temos também no caso da Revolução Russa, uma vez derrubada a monarquia absolutista, um regime constitucional, embo- 
ra muito breve e sob forma republicana, depois um regime revolucionário--radical com guerra civil, sobrevindo, a seguir, a reação termidoriana, a ditadura pessoal (de duração longa e, depois da morte de Stalin, de caráter colegiada), e, agora, isto é, desde 1991, com o colapso da União Soviética, uma surpreendente e imprevista restauração. Na Revolução Francesa, diga-se de passagem, Robespierre e Napoleão dividiram no tempo os papéis que, na Revolução Inglesa, Cromwell desempenhou sozinho e simultaneamente, enquanto na Revolução Russa, Stalin representou aqueles três personagens, tendo desempenhado, sucessivamente, os três papéis, de Cromwell, Robespierre e Napoleão.

A esta altura já deve estar claro que estou tentando explorar menos as diferenças e mais as semelhanças entre as três Revoluções. Registremos, entre as muitas diferenças, em termos sociais, uma participação quase insignificante da classe camponesa na Revolução Inglesa, ao contrário da participação decisiva desta mesma classe nas duas subseqüentes; a presença fundamental da classe operária na Revolução Russa, mas inexistente nas outras duas pelo simples fato de não existir ainda o sistema fabril, o que não significa que o mundo do trabalho artesanal não tenha desempenhado um papel importante, sobretudo na Revolução Francesa, com os sans-culottes.

Registremos, em contrapartida, entre as semelhanças, que, embora com intensidades diferentes, nas três Revoluções, entre as fileiras das respectivas classes dominantes, a nobreza, sobretudo da franja mais alta, a aristocracia (que, mesmo quando não dirige o Estado, ocupa o poder), havia ou um sentimento muito difuso de culpa, ou uma baixa auto-estima, ou, ainda, uma desconfiança com relação ao poder monárquico (e vice-versa, uma desconfiança deste último para com a aristocracia); bem como havia, com relação ao Estado, esse fenômeno conhecido como alienação 
ou deserção dos intelectuais ${ }^{3}$. De sorte que o puritanismo, o iluminismo e o socialismo, antes mesmo de funcionarem como ideologias com base nas quais as três Revoluções foram, respectivamente, levadas a cabo, funcionaram, para muitos integrantes das três nobrezas/aristocracias, como alternativa e solução ideológica ao profundo mal-estar ético-político por eles vivido e que decorria de uma relação histórica tensa e conflituosa dessas mesmas classes com os seus respectivos Estados.

Em outros termos, está-se aqui sustentando a tese de que, se uma Revolução tornou-se possível na Inglaterra, na França e na Rússia, foi porque nos seus antigos regimes produziuse uma fratura, uma divisão fatal no establishment, ou bloco de poder, vale dizer, entre classes e/ou frações de classes dominantes e o poder. A difusão e a força do puritanismo, do iluminismo e do socialismo, nas sociedades inglesa, francesa e russa do antigo regime, era a um só tempo sintoma 46 e conseqüência desse mal-estar espiritual e conflito político no interior de suas respectivas classes dominantes (e destas, obviamente, com relação às classes dominadas). Em contrapartida, e como uma espécie de contraprova ao que se está afirmando, nem na Prússia/Alemanha, nem no Piemonte/ Itália, em 1848/1849 e em 1918/1919, existiu algo semelhante; daí o fracasso, ou melhor, a impossibilidade de uma revolução nesses dois países e nesses dois momentos cruciais.

Continuando, pois, com a comparação, com ênfase na semelhança, lembremos que as historiografias das três Revoluções têm em comum o fato de estarem irremediavelmente marcadas pela divisão entre interpretações a favor e interpretações contrárias ao fenomeno revolucionário. $\mathrm{O}$ que demonstra a impossibilidade de se produzir interpretações que sejam neutras com relação ao seu objeto. Como

\footnotetext{
${ }^{3}$ Sobre esse fenômeno ver Lawrence Stone (2000); Aléxis de Tocqueville (1979); Franco Venturi (2003 e 1972); e, também, Eric Hobsbawm (1977, 1992 e 1995).
} 
lembrou o professor J. Dunn, "Revolução não é um tema banal, e revoluções são acontecimentos especificamente não banais" (1972, p. 1). Nesse sentido, vejamos três considerações de historiadores, com posições ideológicas distintas, a respeito de cada uma das três Revoluções.

Comecemos com o historiador liberal-conservador François Furet que, em livro de 1986, assim caracterizou a historiografia da Revolução francesa:

“[seu] desenvolvimento é comparável ao desenvolvimento da própria Revolução: atravessada de contradições e de batalhas espetaculares, como se o caráter teatral do evento tivesse sido legado a seus historiadores, única parte não dividida de uma herança conflituosa" (Furet, 1986, p. 7).

Por sua vez, o historiador liberal-progressista Lawrence Stone, em livro de 1972, tratando da historiografia da Revolução Inglesa escreveu:

"Pode-se afirmar com segurança que nenhuma controvérsia histórica nos últimos cinqüenta anos atraiu tanta atenção [...] [e] o terreno do desacordo aparece como o mais abrangente possível: desacordo sobre a definição dos termos usados para explicar os fenômenos em questão; desacordo sobre o que aconteceu; desacordo sobre o modo como aconteceu; desacordo sobre as conseqüências do que aconteceu. Uma tal ausência de terreno comum é verdadeiramente rara e sua manifestação parece colocar em dúvida o direito do historiador de ser visto como um pesquisador empírico que fundamenta sua investigação sobre a razão e a prova” (Stone, 2000, p. 78) .

Por último, mas primeiro no tempo, o historiador marxista Isaac Deutscher, em artigo de 1944, afirmava: 
"Nenhum evento na história da humanidade levanta tantas controvérsias violentas quanto as revoluções [...] A controvérsia em torno de cada revolução advém do fato evidente de que uma revolução destrói interesses estabelecidos, ideais, tradições e hábitos, empreendendo sua substituição por um modo de vida totalmente novo. Só isso já bastaria para liberar todas as paixões e fúrias do coração e da mente humanas [...] O que mantém a controvérsia viva, alimentando-a durante várias décadas, são a complexidade do fenômeno e seu caráter multifacetado" (Deutscher, 1991, p. 69).

Acrescente-se a isso que, como bem lembrou o historiador Christopher Hill:

"A história precisa ser reescrita a cada geração, porque, embora o passado não mude, o presente se modifica; cada geração formula novas perguntas ao passado e encontra novas áreas de simpatia à medida que revive distintos aspectos das experiências de suas predecessoras" (1987, p. 32).

E eis explicadas, tanto as polêmicas que opõem os historiadores das três Revoluções, quanto as incessantes reinterpretações de que são objeto.

Voltemos, uma última vez, a Guizot, e à França da Restauração, antes de falar um pouco sobre a atual Restauração na Rússia. Quando, com as jornadas de julho de 1830, a monarquia restaurada dos Bourbons foi derrubada e substituída pela nova dinastia de Orleans, praticamente todos os liberais franceses, seguindo Guizot, viram na Revolução de julho de 1830 o exato equivalente, na França, da Revolução gloriosa de 1688-1689, na Inglaterra. Também o jovem Tocqueville fez essa mesma leitura dos acontecimentos; por isso, mesmo contrariando o seu círculo familiar e de amigos, que permaneceram todos legitimistas, jurou fidelida- 
de ao novo regime, convencido que estava de sua inevitabilidade histórica. Daí por que, no segundo volume de $A$ democracia na América, publicado em 1840, deu ao capítulo XXI o seguinte título: "Por que as Grandes Revoluções se tornarão raras". O que prova que também Tocqueville chegou a compartilhar da interpretação formulada por Guizot segundo a qual o que aconteceu na França em 1830 representava o fim da história. Mas, cerca de cinco anos depois, por volta de 1845, Tocqueville, diferentemente dos demais liberais, deu-se conta de que, como dirá nas Lembranças sobre as jornadas revolucionárias de 1848, havia tomado o fim de um ato, isto é, 1830, pelo fim da peça, isto é, o encerramento do ciclo revolucionário. Daí seu célebre discurso às vésperas da Revolução de 1848, anunciando sua chegada, e daí sua aguda compreensão do acontecimento, ao contrário da perplexidade de Guizot, e de tantos outros liberais, diante desta Revolução que, por não ter lugar no seu horizonte de expectativa da história, foram incapazes de explicar.

Como se vê, a comparação entre os acontecimentos históricos é irresistível, e incontornável, seja ao político, seja ao historiador, mas ela não deixa, contudo, de ser perigosa, pois tanto pode iluminar quanto obscurecer a compreensão do presente, como bem parece ter percebido Tocqueville, o qual, se em A democracia na América constata que "quando o passado não ilumina mais o futuro, o espírito marcha nas trevas", nas Lembranças, observa que "em política se morre, com freqüência, devido ao excesso de memória”. Como quer que seja, a partir da Revolução Francesa de 1789, a Revolução como possibilidade entrou na ordem do dia, e se, à direita do espectro político, os conservadores passaram a temê-la e a exorcizá-la, à esquerda, liberal-democratas e socialistas, de todos os matizes, passaram a esperá-la e até mesmo prepará-la.

Também para lançar luz sobre a criação desse horizonte de expectativa da história, aberto pela Revolução Francesa, 
e sobre o aparecimento dessa nova figura social, o revolucionário profissional, Tocqueville é um testemunho precioso. Em O Antigo Regime e a Revolução, de 1856, assim lamenta o seu surgimento:

"uma raça que se perpetuou e se expandiu em todas as partes civilizadas da terra e que por toda parte preservou a mesma fisionomia, as mesmas paixões, o mesmo caráter. Encontramos esta raça no mundo quando nascemos e ainda está sob nossos olhos".

Na Revolução Russa, como se sabe, não só havia muitos revolucionários profissionais e de todos os matizes, como havia mais de um partido organizado com esse fim, como foi o caso mais notável de Lenin e do partido bolchevique. Em 10 de outubro de 1917, o comitê central do partido se reuniu para discutir o plano de insurreição apresentado por 50 Lenin que, de acordo com a descrição desse acontecimento feita por Deutscher, afirmou:

"Perdeu-se muito tempo [...] a questão é muito aguda e o momento decisivo está próximo [...] temos agora o apoio da maioria. A situação política está agora perfeitamente madura para a passagem do poder" (1972, p. 510).

E, prossegue o historiador:

"Dois membros do comitê central, Zinoviev e Kamenev, discípulos e amigos de Lenin, se opuseram à insurreição. No dia seguinte à reunião, eles declararam: 'Diante da história, diante do proletariado internacional, diante da Revolução russa e da classe operária da Rússia, não temos o direito de jogar todo o futuro na carta da insurreição armada" (Deutscher, 1972, p. 510). 
Na Revolução Francesa, a jornada de 10 de agosto de 1792, que levou à queda da monarquia e à proclamação da República, foi preparada de antemão por uma organização revolucionária, criada dois meses antes, a Comuna Insurrecional de Paris. O fim da monarquia teria merecido o seguinte comentário de Cambon, membro da Convenção Nacional, "cortamos todas as pontes que nos ligavam ao passado”. Esse era o desfecho lógico de uma Revolução cuja ideologia estava voltada para o futuro e cuja Declaração dos Direitos do Homem, como disse Mirabeau, é "aplicável a todos os tempos, todos os lugares e todos os climas".

Na Revolução Inglesa, ao contrário, pelo fato de que praticamente todos os seus revolucionários, fossem moderados, fossem radicais, terem seus olhos postos no passado, numa suposta idade de ouro, não pôde se desenvolver essa consciência de rompimento com o passado. Mas, o fato de a ideologia que alimentou a Revolução Inglesa estar voltada para o passado não significa que foi menos revolucionária que as Revoluções Francesa e Russa, quer com relação ao questionamento da ordem existente, quer com relação à sua destruição, como demonstraram, de perspectivas diferentes, dois livros luminosos, já mencionados e ambos publicados em 1972, As causas da Revolução Inglesa, de Lawrence Stone, e $O$ mundo de ponta-cabeça, de Christopher Hill. Mas significa que, por estar voltada para o passado, a Revolução Inglesa não pôde ser tomada ou adaptada como exemplo para outros países, porque o passado não pode transcender o particular que o vivenciou, diferentemente do que ocorre com o futuro, que pode ser compartilhado por todos, portanto, universalizado.

Vistas nesta perspectiva, isto é, à luz da autoconsciência que os sujeitos têm dos seus próprios atos políticos, as três Revoluções nos oferecem um estranho paradoxo, pois, se na primeira, na Revolução Inglesa, os protagonistas sequer 
parecem saber que estão fazendo uma Revolução, e na última, na Revolução Russa, parecem saber exatamente o que estão fazendo, e podendo-se sustentar que os revolucionários franceses de 1789 exibem um nível de consciência intermediário às outras duas, eis que é possível duvidar que, em termos de controle sobre os acontecimentos e de resultados, esse contraste no nível de consciência dos atores tenha produzido graus de irracionalidade decrescentes entre elas.

Deutscher, no texto já mencionado, cita a seguinte observação de Engels:

"Aqueles que se vangloriam de ter feito uma revolução terminam sempre por descobrir no dia seguinte que não sabiam o que faziam e que a sua revolução não se assemelha em nada àquela que pretendiam fazer" (1972, p. 514).

Esta observação, acrescenta o historiador,

"motivada pela experiência da Revolução francesa, estava destinada a encontrar uma confirmação quase que pontual nas vicissitudes da Revolução Russa e a se refletir nos atos, nas idéias e nas ilusões dos seus protagonistas" (Deutscher, 1972, p. 514).

As ilusões dos protagonistas e o grau de irracionalidade, presentes em todas as revoluções burguesas, se manifestaram na Revolução Russa como que em dose dupla, dado o fato de ela ter sido, ao mesmo tempo, a última revolução burguesa e a primeira proletária. Mais precisamente, não podendo ser nem efetivamente burguesa, nem efetivamente socialista, não pôde evitar a degeneração; aí residindo seu caráter trágico e seus aspectos monstruosos ${ }^{4}$.

${ }^{4}$ Em entrevista concedida para a New Left Review (1978, n $\left.{ }^{\circ} 111\right)$, o historiador 
Tratemos agora, para encerrar, da Restauração russa, a qual, se por um lado, pelo fato de ocorrer mais de setenta anos depois de iniciada a Revolução, e sem o retorno do czarismo, em nada se parece com as restaurações que se seguiram às Revoluções Inglesa e Francesa (ocorridas, respectivamente, 20 e 25 anos depois de iniciadas essas Revoluções e marcadas pelos retornos das antigas dinastias reinantes); por outro lado, tendo em vista o retorno na Rússia do regime capitalista de produção e de concepções e práticas de cultura política típicas do antigo regime, pode-se sustentar a tese de uma restauração russa.

Três exemplos, retirados da Rússia atual, e recentemente veiculados na nossa imprensa, são suficientes para demonstrar a Restauração existente naquele país. Primeiro exemplo: uma associação, ou ONG, russa, intitulada "Comitê das Mães dos Soldados”, que tentou sem sucesso em 2003 fundar o "Partido Único das Mães dos Soldados", mereceu o seguinte comentário de um jornalista russo: "Finalmente um partido sobre o qual não é preciso explicar nada a ninguém". Isto porque a associação e sua tentativa de se transformar em partido nasceram da indignação com a prática da tortura generalizada a que são submetidos todos os recrutas que ingressam no Exército russo e cujo serviço é teoricamente obrigatório. Não foram poucos os recrutas que sofreram danos irreversíveis com as torturas e que, por causa disso, se suicidaram. Segundo exemplo: nas escolas públicas, cresce a cada dia o número de voluntários que dão aulas de religião, sob a alegação de que não se pode alcançar a verdadeira identidade russa sem conhecer o cristianismo ortodoxo.

E. H. Carr agudamente afirma: "Sinto-me agora tentado a dizer que os bolcheviques conquistaram sua vitória em 1917 não a despeito do atraso da economia e da sociedade russas, mas por causa dele”. O que significa dizer que, tendo em vista tais condições e tendo em vista que não mais se tratava, para os bolcheviques, de realizar no país uma revolução burguesa, estavam abertas todas as possibilidades para a Revolução, exceto as possibilidades de que fosse ou efetivamente burguesa ou efetivamente socialista. 
E terceiro: já há analistas fora da Rússia que começam a ver o governo Putin como neofascista, fazendo lembrar a Alemanha no período entre guerras. Ora, o que tudo isso indica senão o fato de que, no executivo, na igreja e no exército, os três pilares do Antigo Regime estão de volta? Não se assiste, com efeito, ao espetáculo de um presidente que acumula mais poder e tão permanente quanto um czar, de uma Igreja que volta a doutrinar os russos num cristianismo retrógrado e obscurantista, e de um exército cujo barbarismo é o mesmo da época de Tolstoi, que conta o seguinte episódio para ilustrá-lo: "Um oficial, vendo um sargento espancar impiedosamente um soldado, grita-lhe: o senhor não leu a Bíblia? E o sargento, sem parar de espancar o soldado, respondelhe: E o senhor não leu o regulamento?”

Neste momento, em que a Revolução de 1917 cumpre seu nonagésimo ano, li mais de um artigo recente, tanto de especialistas em particular, quanto de jornalis54 tas em geral, em que se afirma, com convicção, à direita, que a Revolução de Outubro está definitivamente morta, e, à esquerda, que continua viva. Como vimos, isso é inevitável. Mas também é absolutamente inútil, pelo menos em termos de interpretação, de historiografia, pois tais escritos, não sendo críticos, em nada contribuem para o conhecimento histórico. Sendo crítica, uma interpretação que, como também vimos, não pode deixar de ser a favor ou contra Outubro de 1917, poderá, contudo, desde que tenha rigor, qualidade e imaginação, ser útil e emitir luz capaz de provocar nossa imaginação e reflexão.

Como ocorre, para dar um último exemplo, com as interpretações luminosas de dois consagrados historiadores/jornalistas, o liberal inglês E. H. Carr e o marxista polonês, radicado na Inglaterra, Isaac Deutscher (ambos já falecidos, em 1982 e 1967, respectivamente), escritas em 1967, por ocasião do cinqüentenário da Revolução russa. A interpretação de Carr é o ensaio intitulado "O lugar da Revolu- 
ção Russa na História”, salvo engano, nunca traduzido para o português, e a interpretação de Deutscher é o livro $A$ revolução inacabada, publicado pela editora Civilização Brasileira um ano depois, em 1968. As interpretações desses dois historiadores, amigos um do outro, elaboradas no contexto da intensa polarização ideológica do período da Guerra Fria, destacam-se por sua posição independente e heterodoxa com relação aos seus respectivos campos teóricos, o liberal e o marxista, e por sua abordagem ao mesmo tempo positiva e crítica da Revolução Russa, constituindo-se numa raridade em termos de historiografia. Lendo-se hoje esses dois textos, verifica-se que, se, como não poderia deixar de ser, estão datados, também continuam atuais e vigorosos, posto que seus autores ao escrevê-los souberam, transcendendo o contexto mais imediato e menos profundo, elevar-se $a u$ dessus de la mêlée $e^{5}$.

Termino com a interpretação de Deutscher, na qual se afirma que a Revolução Russa "de maneira nenhuma já chegou a seu termo final" e que ela "sobreviveu a todos os pos-

\footnotetext{
${ }^{5}$ Na interpretação de Carr, destaca-se, entre tantas considerações iluminadoras sobre a Revolução Russa (e as precedentes, a inglesa e a francesa), sua explicação sobre o porquê da alta consciência revelada pelos lideres revolucionários russos, sobretudo Lenin. Para Carr, isto se deve ao próprio desenvolvimento da economia e da ciência que permite não só dominar/controlar a economia e a natureza, mas também a sociedade e, o que é mais importante, transformar em instrumentos visando a determinados fins. Segundo Carr, o leninismo é o marxismo adaptado, ou que responde a essa nova situação objetiva que começa a caracterizar a realidade ocidental nas últimas décadas do século XIX. Por outro lado, no livro Karl Marx, publicado em 1934, Carr profeticamente afirmou: "Mesmo se o futuro próximo produzir uma extensão e uma intensificação do governo de massa, a tendência inveterada do homem em se individualizar irá em última análise reaparecer; e a menos que todas as analogias históricas sejam falsas, uma nova diferenciação com relação às massas irá levar a um novo renascimento do humanismo. Ninguém se preocupará em profetizar quando e como esta revolução irá ocorrer. Mas quando ela estiver consumada, a época marxista da história terá chegado ao fim”. Deutscher (1968a, "Entre o Passado e o Futuro", p. 244) definiu Carr como "um dos liberais britânicos mais inortodoxos, radicais e de espírito aberto de sua geração”, e Perry Anderson (1991, p. 7), afirma que o marxista Deutscher destaca-se, entre outras virtudes intelectuais, por sua "independência moral, seu internacionalismo espontâneo, seu intransigente espírito revolucionário" (Prefácio ao livro de Deutscher, Marxismo, guerras e revoluções).
} 
síveis agentes de restauração", o que, visto de hoje, evidenciaria que a interpretação está irremediavelmente datada e superada. Também se lê que:

"O regresso dos Bourbons e dos Stuarts ensinou ao povo muito mais e melhor do que os puritanos, jacobinos ou bonapartistas o fizeram, que não existe caminho de volta ao passado; que o trabalho básico de uma revolução é irreversível e deve ser salvaguardado para o futuro. Sem querer, a restauração reabilita, assim, a revolução ou, pelo menos, as suas realizações essenciais e racionais" (Deutscher, 1968a).

Só o futuro dirá se isso poderá ou não acontecer também com a Restauração russa.

\section{Modesto Florenzano}

56 é professor de História Moderna do Departamento de História da FFLCH/USP

\section{Referências bibliográficas}

ANDERSON, P. 1991. "Prefácio". In: DEUTSCHER, I. Marxismo, guerras e revoluções. São Paulo: Ática.

BRINTON, C. 1958. Anatomia das revoluções. Rio de Janeiro: Fundo de Cultura.

CARR, E. H. 1934. Karl Marx: a study in fanaticism. Londres: Dent. . 1969. 1917: before and after. Londres: Macmillan and Co. Ltd. . 1978. Entrevista a New Left review, n. 111.

DEUTSCHER, I. 1968a. A revolução inacabada. Rússia 1917-1967. Rio de Janeiro: Civilização Brasileira.

. 1968b. Ironias da história. Rio de Janeiro: Civilização Brasileira. . 1972. The New Cambridge modern history, vol. XII. Milão: Garzanti. 1991. Marxismo, guerras e revoluções. São Paulo: Ática.

DUNN, J. 1972. Modern revolutions: an introduction to the analysis of a political phenomenon. Cambridge: Cambridge University Press.

FERRO, M. 1984. O Ocidente diante da Revolução soviética. São Paulo: Brasiliense. 
FURET, F. 1986. La gauche et la Révolution au milieu du XIX ${ }^{e}$ siècle - Edgar Quinet et la question du Jacobinisme 1865-1870. Paris: Hachette.

HILL, C. 1987. O mundo de ponta-cabeça. São Paulo: Companhia das Letras.

HOBSBAWM, E. 1977. A era do capital 1848-1875. Rio de Janeiro: Paz e Terra. . 1992. A era dos impérios 1875-1914. Rio de Janeiro: Paz e Terra. . 1995. A era dos extremos. O breve século XX 1914-1991. São Paulo: Companhia das Letras. 1996. Ecos da Marselhesa: dois séculos revêem a Revolução Francesa. São Paulo: Companhia das Letras.

LUTAUD, O. 1990. "Emprunts de la Révolution française a la première Révolution anglaise". Revue d'Histoire Moderne et Contemporaine.

RICHARDSON, R. C. 1991. The debate on the English Revolution revisited. Londres: Routledge.

SKOCPOL, T. S. 1985. Estado e revoluções sociais: análise comparativa da França, Rússia e China. Lisboa: Editorial Presença.

STONE, L. 2000. Causas da Revolução inglesa 1529-1642. Bauru, SP: Edusc.

TOCQUEVILLE, A. de. 1979. O Antigo Regime e a revolução. Brasília: Ed. UnB.

VENTURI, F. 1972. Il populismo russo. Turim: Einaudi. . 2003. Utopia e reforma no Iluminismo. Bauru, SP: Edusc. 


\section{A REVOLUÇÃO RUSSA EM PERSPECTIVA HISTÓRICA E COMPARADA}

\section{MODESTO FLORENZANO}

Sugere-se uma comparação da Revolução Russa de 1917 com a Revolução Francesa de 1789 e a Revolução Inglesa

220 de 1640. Se uma Revolução tornou-se possível na Inglaterra, na França e na Rússia, foi porque, nos seus antigos regimes, produziu-se uma divisão fatal no establishment, vale dizer, entre classes e/ou frações de classes dominantes e o poder. A difusão e a força do puritanismo, do iluminismo e do socialismo, nas sociedades inglesa, francesa e russa do antigo regime, eram a um só tempo sintoma e conseqüência desse mal-estar espiritual e desse conflito político no interior de suas respectivas classes dominantes (e destas, obviamente, com relação às classes dominadas). Em contrapartida, e como uma espécie de contraprova ao que se está afirmando, nem na Prússia/Alemanha, nem no Piemonte/ Itália, em 1848-1849 e em 1918-1919, existiu algo semelhante; daí a impossibilidade de uma revolução nesses dois países e nesses dois momentos cruciais.

Palavras-chave: Revolução Russa de 1917; Revolução Francesa de 1789; Revolução Inglesa de 1640; História comparada. 


\section{THE RUSSIAN REVOLUTION IN HISTORICAL AND COMPARATIVE PERSPECTIVE}

The article suggests a comparative view on the Russian Revolution of 1917, the French Revolution of 1789 and the English Revolution of 1640. It argues that a revolution became possible in England, France and Russia because a fatal split broke the old regime's establishment, that is to say, a divide between classes, and/or fractions of upper classes, and power. The strenght and diffusion of puritanism, enlightenment and socialism througout old regime's English, French and Russian societies, were both the sign and the effect of that spiritual malaise and that political conflict within their respective upper classes (and so, of course, in relation to their subordinate classes). On the other hand, as a counterproof of what it is just said, neither Prussia/Germany nor Piemont/Italy, in 1848-1849 and 1918-1919, had something similar; so that a revolution was impossible in those countries and crucial moments.

Keywords: The 1917 Russian Revolution; The 1789 French Revolution; The 1640 English Revolution; Comparative history. 